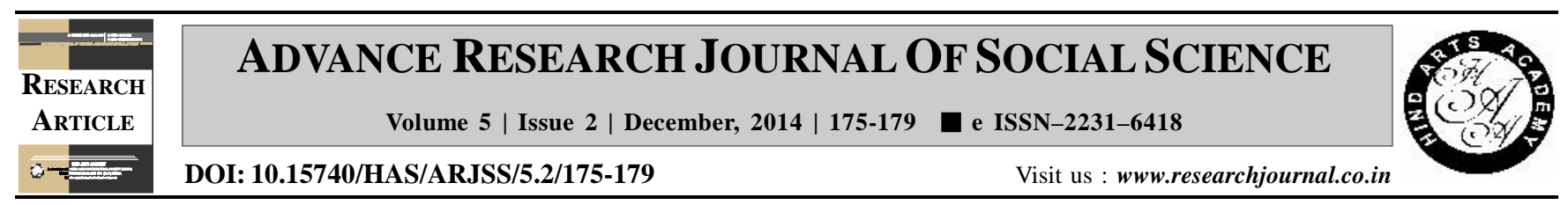

\title{
Knowledge of homemakers regarding base materials used for cooking utensils
}

D. Mittal, M. Sidhu* and S. Bal

Department of Family Resource Management, College of Home Science, Punjab Agricultural University, LUDHIANA (PUNJAB) INDIA

(Email: muninderkaur@pau.edu)

\section{ARTICLE INFO :}

$\begin{array}{lll}\text { Received } & : & 28.08 .2014 \\ \text { Revised } & : & 06.11 .2014 \\ \text { Accepted } & : & 20.11 .2014\end{array}$

KEY WORDS :

Food grade plastics, Knowledge, Non-food grade plastics, Stoneware, Surgical steel

HOW TO CITE THIS ARTICLE :

Mittal, D., Sidhu, M. and Bal, S. (2014). Knowledge of homemakers regarding base materials used for cooking utensils. Adv. Res. J. Soc. Sci., 5 (2) : 175-179.

*Author for correspondence

\begin{abstract}
One cannot imagine any home without any cooking utensil. Satisfactory use of these utensils include their correct selection, arrangement, use and care so that homemaker can accomplish her work without any physical and mental stress. Vessels and pots are usually made from a wide range of metals. The homemaker is always interested in the properties of the materials from which her kitchen appliances and utensils are made. The knowledge enables her to select with confidence the best material for a given task and to care for it successfully. Due to the dual responsibility of the homemakers at home as well as at work places outside the home, there is a greater pressure for productivity enhancement and quality work. It was felt important to study the general awareness of the end users regarding the different materials used for cooking vessels used in any Indian kitchens. Hence, the choice of suitable utensils of right metal and appropriate size has become complex subject for the homemakers. Study revealed that all the rural and urban respondents were aware of aluminium and hindalium metal that was used for the construction of utensils for Indian cooking. Hindalium was the most commonly used material for cooking utensils followed by aluminium, stainless steel. Earthenware, chinaware and stoneware were the least used materials by both the categories of the respondents. All respondents found aluminium, hindalium and stainless steel cookware 'easy to clean' as well as 'durable materials'. None of the selected respondents reported that glass, earthenware, chinaware, stoneware and pottery utensils were durable.
\end{abstract}

